\title{
ADAPTASI NEW ENTRANTS MENGGUNAKAN STRATEGI MARKETING DENGAN WORD OF MOUTH TERHADAP LOYALITAS PELANGGAN
}

\author{
Jean Richard Jokhu \\ Jurusan Manajemen, Universitas Presiden Bekasi \\ Email: jean.richard@president.ac.id
}

Masuk : 30-03-2020, revisi: 16-04-2020, diterima untuk diterbitkan : 16-04-2020

\begin{abstract}
ABSTRAK
Penelitian ini berupaya untuk mengetahui strategi perusahaan new entrants dalam industri sportswear di Indonesia. Dengan menggunakan perspektif WOM sebagai salah satu faktor lingkungan yang memengaruhi loyalitas pelanggan. Dengan menggunakan proses analisis konfirmatori penelitian ini menggunakan PLS dalam menganalisis data. Jumlah responden berhasil dikumpulkan 77 sampel. Hasilnya penelitian ini menemukan promosi berperan penting dalam strategi Onitsuka memenangkan loyalitas pasar Indonesia. WOM juga berperan penting dalam meningkatkan loyalitas pasar Indonesia. Lebih lanjut penelitian ini menemukan strateegi perusahaan yaitu marketing 4Ps mampu menjelaskan WOM secara simultan. Dengan menggunakan strategi marketing yang berfokus pada harga, promosi, lokasi, dan produk perusahaan dapat meningkatkan WOM yang beredar di masyarakat sehingga dapat memengaruhi loyalitas pelanggan bagi perusahaan new entrants khususnya dalam industri sportswear di Indonesia
\end{abstract}

Kata Kunci: Marketing Mix, Word of Mouth, Loyalitas Pelanggan

\section{ABSTRACT}

This study purposed is to find out the strategy of the new entrants company in the sportswear industry in Indonesia. By using the WOM perspective as one of the environmental factors that influence customer loyalty. By using the confirmatory analysis process this study uses PLS in analyzing data. The number of respondents successfully collected 77 samples. As a result this research found that promotion is important for Onitsuka strategy to win the loyalty of the Indonesian market. WOM also plays an important role in increasing the loyalty of the Indonesian market. Furthermore, this study found that 4Ps marketing companies were able to explain WOM simultaneously. Adopting marketing strategies that focus on price, promotions, locations and company goods can increase WOM's circulation in the society in order to thrust consumer loyalty toward new entrant companies, particularly in Indonesia's sportswear industry

Keywords: Marketing Mix, Word of Mouth, Customer Loyalty

\section{PENDAHULUAN}

\section{Latar Belakang}

Pertumbuhan industri sportswear di dunia mengalami peningkatan yang luar biasa hal ini terlihat dari laporan tahun 2019 tercatat lebih dari 30\% (eatspring investment, 2020). Dengan perubahan gaya hidup masyarkat global dari pakaian olahraga menjadi athleisure yaitu pakaian yang difungsikan untuk olahraga bergeser menjadi pakaian sehari - hari baik formal maupun non-formal. Pergeseran arus fashion ini mendorong permintaan akan sportswear meningkat di Asia. Saat ini Indonesia merupakan salah satu pasar terbaik dalam industri ini. Dengan jumlah penduduk lebih dari 250 juta orang, Indonesia merupakan pangsa pasar gemuk bagi perusahaan sportswear global. Dengan aturan car free day dan pusat latihan yang banyak di perkotaan mengeser pola hidup masyarakat Indonesia menjadi lebih fleksibel dan memilih untuk menggunakan pakaian yang dapat mengakomodasi aktivitas olahraga dan kasual.

Melihat peluang tersebut Onitsuka masuk sebagai pemain baru dalam pasar sportswear di Asia tenggara. Dalam tiga tahun belakang Onitsuka melakukan ekspansi besar - besaran guna meraup pasar dengan membuka outlet di India (2019), New York (2019), dan Indonesia (2017) (Damar, 2017). Indonesia merupakan salah satu pasar terbesar bagi industri sportswear dengan pertumbuhan sebesar $13 \%$ pertahun. Namun, ukuran tersebut masih tergolong rendah untuk kawasan Asia tenggara jika dibandingkan dengan 
Singapura dan Malaysia. Menurut Global Business Guide Indonesia ("Indonesia Sportswear Industry | GBG," 2017) jika dilihat dari jumlah penduduk Indonesia merupakan pasar potensial dalam sportswear dengan $43 \%$ orang berusia dibawah 30 tahun maka industri ini dapat bertumbuh pesat dalam tiga tahun kedepan.

Onitsuka terkenal di Jepang sebagai perusahaan sportswear yang memiliki daya saing dalam bentuk sepatunya dapat digunakan dalam latihan fisik maupun formal. Hal ini dapat menjadi keunggulan daya saing bagi perusahaan baru yang akan masuk ke pasar Indonesia. Penelitian ini bertujuan untuk menganalisis strategi marketing yang digunakan oleh Onitsuka sebagai merk baru di Indonesia agar dapat bersaing dengan perusahaan besar seperti Nike dan Adidas. Dengan menggunkan teori strategi marketing $4 P s$ sebagai faktor yang mempengaruhi loyalitas pelanggan (Ang et al., 2018)dan bagaimana word of mouth mampu memengaruhi loyalitas pelanggan secara positif. Selain itu penelitian ini akan mencoba melihat seberapa besar pengaruh strategi marketing 4Ps terhadap word of mouth. Menurut Saleem et al. (2018)

Menurut Ang et al. (2018) strategi pemasaran yang umum dipakai oleh ritel adalah 4Ps yaitu place, price, promotion, dan price. Faktor - faktor ini banyak digunakan untuk meneliti seberapa besar pengaruh sebuah strategi marketing terhadap loyalitas (Harsono, 2016; Sriram et al., 2019; Sudari et al., 2019). Dalam penelitian Ang et al., (2018) dalam industri sports wear strategi marketing sangat berperan dalam meningkatkan loyalitas konsumen. Berbeda dengan strategi marketing word of mouth adalah perspektif yang diciptakan antara masyarkat guna memperoleh informasi akan sebuah produk (Saleem et al., 2018). Word of Mouth (WOM) diciptakan oleh pasar dengan demikian perusahaan tidak bisa mengontrol secara penuh pengelolaan sebuah informasi dalam sebuah pasar (La Pointe, 2011; Warrington, 2002). Menurut Maulani (2017) marketing mix dapat memengaruhi citra dari pemasar dalam masyarakat. Aktifnya marketing mix juga dilihat dapat berperan dalam industri FMCG (Fast Moving Consumer Goods) terhadap WOM dengan menggunakan influencer (Dost et al., 2019). Penelitian akan pengaruh Marketing mix dengan WOM dan loyalitas pelanggan perlu di perdalam dalam industri lain. Pertanyaan akan pengaruh strategi ini dapat digeneralisasi atau dibatasi oleh industri FMCG saja atau dapat dikembangkan ke dalam sektor industri lain. Dengan demikian penelitian ini melihat pentingnya untuk meanalisis strategi yang dapat digunakan oleh perusahaan baru atau new entrants seperti Onitsuka dengan menggunakan perspektif strategi marketing 4Ps dan WOM sebagai faktor lingkungan yang turut memengaruhi loyalitas pelanggan. Selain itu penelitian ini juga mencoba menggali lebih dalam akan pengaruh marketing mix secara simultan terhadap WOM dalam konteks industri sportswear.

\section{METODE PENELITIAN}

Penelitian ini menggunakan metode kuantitatif dengan analisis konfirmatori. Hal ini bertujuan untuk membuktikan peran marketing mix sebagai landasan teori perusahaan retail dalam melakukan strategi pemasaran masih cukup atau sudah usang dalam persaingan industri sportswear. Proses pengambilan sampel penelitian ini menggunakan metode convinience sampling guna menyaring data responden yang sudah melakukan pembelian terhadap sepatu onitsuka. Pemilihan metode convinience sampling karena dalam penelitian ini karena menggunakan metode kuantitaif. Penggunaan convinience sampling dinilai dapat memberikan pengertian yang dapat digeneralisasi sedangkan purposive sampling merupakan metode pengumpulan sampel yang bertujuan untuk memperdalam suatu teori dengan demikian lebih layak untuk digunakan dalam penelitian qualitatif (Etikan et al., 2016).

Dalam penelitian ini pernyataan dalam kuesioner dibentuk dari penelitian-penelitian terdahulu guna memperkuat expert validity dari setiap variabel penelitian. Total responden yang diperoleh adalah dari penyebaran kuesioner secara online dan offline di JABODETABEK (Jakarta, Bogor, 
Depok, Tangerang, dan Bekasi). Dengan total kuesioner yang dikumpulkan berjumlah 137 sampel, kemudian dengan melalui proses pembersihan data dari outliers diperoleh hasil sebanyak 77 orang. Dengan jumlah sampel sebanyak ini, maka proses analisis data lebih lanjut menggunakan Partial Least Square (PLS). Menurut Hair et al. (2019) aplikasi PLS-SEM dapat digunakan dalam penelitian yang memiliki distribusi data yang tidak normal dan jumlah sampel yang sedikit. Dengan demikian penelitian ini menggunakn PLS untuk menjelaskan temuan yang diperoleh dari hasil survey.

Dalam penelitian ini kuesioner yang digunakan diperoleh dari penelitian - penelitian terdahulu sehingga dapat memenuhi kriteria expert validity dari sebuah teori. Expert validity bertujuan untuk memverifikasi setiap indikator dalam pertanyaan yang digunakan sesuai dengan basis teori yang coba dijelaskan dalam sebuah penelitian sehingga penelitian ini dapat dinyatakan valid dalam menggambarkan suatu teori (Anderson et al., 1991). Lebih lanjut operasional variabel dapat dilihat dalam tabel 1 .

Tabel 1. Operasional Variabel

Sumber: Hasil olah peneliti

\begin{tabular}{|c|c|c|c|}
\hline Variabel & Indikator & Pernyataan & Sumber \\
\hline \multirow[t]{4}{*}{ Price } & Pricel & $\begin{array}{l}\text { Harga yang ditawarkan Onitsuka Tiger } \\
\text { sangat bersaing }\end{array}$ & \multirow{15}{*}{$\begin{array}{c}\text { (Mulyana \& } \\
\text { Management, 2018; } \\
\text { Othman et al., } \\
\text { 2019; Setiawan, } \\
\text { 2019; Wu \& Li, } \\
\text { 2018) }\end{array}$} \\
\hline & Price2 & $\begin{array}{l}\text { Saya tertarik menjadi member Onitsuka } \\
\text { Tiger karena diskon } 10 \%\end{array}$ & \\
\hline & Price3 & $\begin{array}{l}\text { Variasi harga produk-produk Onitsuka } \\
\text { Tiger sangat menarik }\end{array}$ & \\
\hline & Price4 & $\begin{array}{l}\text { Program potongan harga yang } \\
\text { diberikan Onitsuka Tiger sangat } \\
\text { menarik }\end{array}$ & \\
\hline \multirow[t]{5}{*}{ Promotion } & Promol & $\begin{array}{l}\text { Saya tertarik dengan promosi Onitsuka } \\
\text { Tiger lewat media sosial (Instagram, } \\
\text { Facebook, Twitter, dll) }\end{array}$ & \\
\hline & Promo2 & $\begin{array}{l}\text { Promosi yang dibuat Onitsuka Tiger } \\
\text { membuat saya ingin membeli } \\
\text { produknya }\end{array}$ & \\
\hline & Promo3 & $\begin{array}{l}\text { Promosi Onitsuka Tiger lebih mudah } \\
\text { dipahami daripada pesaing }\end{array}$ & \\
\hline & Promo4 & $\begin{array}{l}\text { Promosi Onitsuka Tiger lebih mudah } \\
\text { ditemukan daripada pesaing }\end{array}$ & \\
\hline & Promo5 & $\begin{array}{l}\text { Saya selalu menantikan promosi } \\
\text { Onitsuka Tiger }\end{array}$ & \\
\hline \multirow[t]{5}{*}{ Product } & Product1 & $\begin{array}{l}\text { Saya tertarik dengan variasi jenis } \\
\text { produk Onitsuka Tiger }\end{array}$ & \\
\hline & Product2 & $\begin{array}{l}\text { Design produk Onitsuka Tiger sangat } \\
\text { unik }\end{array}$ & \\
\hline & Product3 & $\begin{array}{l}\text { Warna produk Onitsuka Tiger sangat } \\
\text { beragam }\end{array}$ & \\
\hline & Product4 & $\begin{array}{l}\text { Produk Onitsuka Tiger sangat nyaman } \\
\text { digunakan }\end{array}$ & \\
\hline & Product5 & $\begin{array}{l}\text { Ukuran produk Onitsuka Tiger banyak } \\
\text { variasi }\end{array}$ & \\
\hline Place & Place1 & $\begin{array}{l}\text { Lokasi toko Onitsuka Tiger mudah } \\
\text { ditemukan }\end{array}$ & \\
\hline
\end{tabular}




\begin{tabular}{|c|c|c|c|}
\hline & Place2 & \multicolumn{2}{|l|}{$\begin{array}{l}\text { Saya merasa nyaman berada di toko } \\
\text { Onitsuka Tiger }\end{array}$} \\
\hline & Place3 & \multicolumn{2}{|l|}{$\begin{array}{l}\text { Lokasi toko Onitsuka Tiger yang } \\
\text { berada di mall memudahkan saya untuk } \\
\text { berbelanja. }\end{array}$} \\
\hline & Place4 & \multicolumn{2}{|l|}{ Design toko Onitsuka Tiger yang unik } \\
\hline & Place5 & \multicolumn{2}{|l|}{$\begin{array}{l}\text { Saya akan masuk ke dalam toko } \\
\text { Onitsuka Tiger ketika melihat storenya } \\
\text { di mall }\end{array}$} \\
\hline \multirow[t]{4}{*}{$\begin{array}{l}\text { Word Of } \\
\text { Mouth }\end{array}$} & WOM1 & $\begin{array}{l}\text { Saya mendapat informasi tentang } \\
\text { Onitsuka Tiger dari Teman }\end{array}$ & \multirow{4}{*}{$\begin{array}{c}\text { (Lee, Tang, Yip, \& } \\
\text { Sharma, 2018; } \\
\text { Saleem et al., 2018; } \\
\text { Shaikh, Karjaluoto, } \\
\text { \& Häkkinen, 2018) }\end{array}$} \\
\hline & WOM2 & $\begin{array}{l}\text { Saya disarankan untuk membeli } \\
\text { produk Onitsuka Tiger }\end{array}$ & \\
\hline & WOM3 & $\begin{array}{l}\text { Komentar di media sosial } \\
\text { mempengaruhi penilaian saya terhadap } \\
\text { produk Onitsuka Tiger }\end{array}$ & \\
\hline & WOM4 & $\begin{array}{l}\text { Saya sering bertukar informasi tentang } \\
\text { Onitsuka Tiger }\end{array}$ & \\
\hline \multirow[t]{5}{*}{ Loyalty } & Loyalty1 & $\begin{array}{l}\text { Saya akan membeli produk Onitsuka } \\
\text { Tiger untuk keseharian }\end{array}$ & \multirow{5}{*}{$\begin{array}{c}\text { (Mulyana \& } \\
\text { Management, 2018; } \\
\text { Othman et al., } \\
\text { 2019; Sari, 2017; } \\
\text { Setiawan, 2019; Wu } \\
\text { \& Li, 2018) }\end{array}$} \\
\hline & Loyalty2 & $\begin{array}{l}\text { Saya akan membeli produk Onitsuka } \\
\text { Tiger ketika ada model baru }\end{array}$ & \\
\hline & Loyalty3 & $\begin{array}{l}\text { Saya akan membeli produk Onitsuka } \\
\text { Tiger ketika ada promo }\end{array}$ & \\
\hline & Loyalty 4 & $\begin{array}{l}\text { Saya akan mengajak teman saya untuk } \\
\text { membeli Onitsuka Tiger }\end{array}$ & \\
\hline & Loyalty5 & $\begin{array}{l}\text { Saya akan mengajak keluarga saya } \\
\text { untuk membeli Onitsuka Tiger }\end{array}$ & \\
\hline
\end{tabular}

Hasil suvei dapat dilihat dalam tabel 2, diperoleh jumlah responden yang sedikit didominasi oleh pria. Dalam pie chart menunjukan dari 77 orang responden $51 \%$ adalah pria sedangkan sisanya merupakan perempuan (48\%). Berbeda dengan distribusi responden berdasarkan usia yang jauh didominasi oleh 20 - 25 tahun sebanyak 64 orang dari 77 responden (83\%) dibandingkan dengan usia di atas 30 tahun yang hanya sebesar 3\%. Hal ini disebabkan oleh target pasar dari Onitsuka sendiri adalah customer dengan usia muda (20-30 tahun) atau golongan milenial sehingga banyak responden yang membeli produk Onitsuka adalah kaum muda yang aktif. Selanjutnya profil terakhir adalah distribusi responden berdasarkan besarnya pengeluaran, yang didominasi oleh rentan pengeluaran satu juta rupiah hingga lima juta rupiah per bulan yaitu sebesar 63 orang (83\%). Hasil pengamatan ini dapat disimpulkan bahwa Onitsuka berhasil menggapai target pasar yaitu para milenial seperti yang terlihat dari hasil distribusi responden yang sangat tinggi diusia tersebut. Selanjutnya gender tidak berpengaruh besar preferensinya terhadap produk Onitsuka hal ini terlihat dari jumlah responden yang relatif seimbang antara pria dan wanita dalam persebaran sampel dalam penelitian ini. 
Tabel 2 Profil Responden

Sumber: kuesioner

\begin{tabular}{lll}
\hline \hline & Jumlah & Persentase (\%) \\
\hline Gender & & \\
Pria & 40 & 51 \\
Wanita & 37 & 48 \\
\hline Usia & & \\
$<20$ Tahun & 8 & 10 \\
20-25 Tahun & 64 & 83 \\
25-30 Tahun & 3 & 4 \\
>30 Tahun & 2 & 3 \\
\hline Pengeluaran Bulanan & & \\
$<$ Rp 1.000.000 & 5 & 10 \\
Rp 1.000.000- Rp 5.000.000 & 63 & 83 \\
Rp 5.000.000- Rp 10.000.000 & 7 & 4 \\
$>$ Rp 10.000.000 & 2 & 3 \\
\hline
\end{tabular}

\section{HASIL DAN PEMBAHASAN}

Uji validitas dilakukan dengan menggunakan software Smart PLS 3.0. Hasil uji validitas dan reliabilitas dalam PLS diperoleh dengan melalui nilai loading dari setiap indikator. Berdasarkan tabel 3 diperoleh nilai loading yang baik (Loading value > 0.5) dari setiap indikator untuk digunakan pada proses selanjutnya. Selain nilai loading untuk melihat reliabilitas dan validitas dari setiap variabel dapat dilihat dari nilai Composite reliability (CR) dan Average variance extracted (AVE). Nilai CR dari setiap variabel telah memenuhi syarat reliabilitas karena memiliki nilai lebih dari 0.7 (Hair et al., 2019). Demikian juga nilai AVE dalam setiap variabel telah memenuhi syarat minimum yaitu 0.5 (Ahmad et al., 2016)

Tabel 3. Ringkasan hasil reflektif Outer model PLS

Sumber : Smart PLS 3.0

\begin{tabular}{|c|c|c|c|c|}
\hline & \multicolumn{3}{|c|}{ Sumber : Smart PLS 3.0} & \multirow[b]{2}{*}{$\begin{array}{c}\text { Average } \\
\text { Variance } \\
\text { Extracted }\end{array}$} \\
\hline & Indikator & Loading & $\begin{array}{l}\text { Composite } \\
\text { Reliability }\end{array}$ & \\
\hline \multirow[t]{4}{*}{ Price } & Price1 & 0.876 & 0.915 & 0.686 \\
\hline & Price2 & 0.808 & & \\
\hline & Price3 & 0.860 & & \\
\hline & Price4 & 0.869 & & \\
\hline \multirow[t]{5}{*}{ Promotion } & Promo1 & 0.852 & 0.942 & 0.765 \\
\hline & Promo2 & 0.871 & & \\
\hline & Promo3 & 0.896 & & \\
\hline & Promo4 & 0.869 & & \\
\hline & Promo5 & 0.884 & & \\
\hline \multirow[t]{5}{*}{ Product } & Product1 & 0.822 & 0.894 & 0.629 \\
\hline & Product2 & 0.786 & & \\
\hline & Product3 & 0.759 & & \\
\hline & Product4 & 0.778 & & \\
\hline & Product5 & 0.817 & & \\
\hline
\end{tabular}




\begin{tabular}{lllll}
\hline Place & Place1 & 0.786 & 0.916 & 0.686 \\
\cline { 2 - 4 } & Place2 & 0.854 & & \\
\cline { 2 - 4 } & Place3 & 0.758 & & \\
\cline { 2 - 5 } & Place4 & 0.893 & & 0.682 \\
\cline { 2 - 5 } Wlace5 & 0.851 & & \\
\hline Loyalty & WOM1 & 0.766 & 0.895 & 0.706 \\
\cline { 2 - 5 } & WOM2 & 0.851 & & \\
\cline { 2 - 5 } & WOM3 & 0.802 & & \\
\cline { 2 - 5 } & WOM4 & 0.879 & & \\
\cline { 2 - 5 } & Loyalty1 & 0.870 & & \\
\cline { 2 - 5 } & Loyalty2 & 0.800 & & \\
\cline { 2 - 5 } & Loyalty3 & 0.709 & & \\
\cline { 2 - 5 } & Loyalty5 & 0.891 & & \\
\hline
\end{tabular}

Berdasarkan hasil uji inner dan outer model diperoleh nilai T untuk menguji signifikansi dari hipotesis penelitian. Dengan menggunakan proses bootsraping diperoleh hasil analisis hipotesis dalam tabel 4. Berdasarkan hasil uji analisis diperoleh tiga hipotesis diterima dan tiga hipotesis ditolak dalam gambar 1. Dalam H1 yang menjelaskan hubungan antara harga dengan loyalitas pelanggan diperoleh nilai $\mathrm{t}$ sebesar 1.222 maka korelasi antara kedua variabel tersebut dinyatakan tidak signifikan. Berbeda dengan $\mathrm{H} 2$ yang menjelaskan hubungan antara Promosi dengan loyalitas pelanggan diperoleh hasil 2.163 maka dapat dismpulkan ada hubungan positif antara promosi dengan loyalitas pelanggan. Pada H3, hubungan antara produk dengan loyalitas pelanggan diperoleh hasil yang tidak signifikan hal ini tercermin dengan nilai t sebesar 0.785 .

Demikian juga lokasi yang dijelaskan dengan H4 memperoleh nilai korelasi yang tidak signifikan yaitu 1.652. Berbeda dengan H5 yang diperoleh hasil yang signifikan antara hubungan word of mouth dengan loyalitas pelanggan. Berdasarkan temuan - temuan di atas diperoleh hasil yang cukup mengejutkan dimana marketing mix yang jelaskan melalui $\mathrm{H} 1$ - H4 hanya dapat mempengaruhi loyalitas konsumen melalui promosi. Peran dari media sosial sangat berpengaruh terhadap perpekstif yang dibentuk oleh media sosial. Dengan menggunakan media sosial peran promosi dapat lebih maksimal terhadap loyalitas konsumen jika dilihat dari produk onitsuka. Temuan lain dalam penelitian ini adalah peran dari variabel produk, lokasi, dan harga ditemukan tidak signifikan loyalitas pelanggan sepatu onitsuka. Di sisi lain word of mouth menjadi salah satu faktor dalam meningkatkan loyalitas diperoleh hasil signifikan positif terhadap loyalitas. Hal ini membuktikan word of mouth pelanggan. Selanjutnya pada H6 diperoleh hasil yang signifikan hal ini tercermin dari nilai adjusted $\mathrm{R}$ square sebesar 0.643 . Hal ini menjelaskan bahwa marketing mix dapat menjelaskan variabel word of mouth sebesar $64 \%$ sedangkan $36 \%$ dapat diperoleh dari variabel yang tidak ter-amati. Temuan ini mengkonfirmasi penelitian sebelumnya dalam industri FMCG akan pengaruh promosi terhadap WOM (Dost et al., 2019). Peran dari marketing mix juga sangat penting dalam perspektif yang dibangun dalam WOM pasar sportswear. Informasi yang berkembang melalui media sosial melalui strategi marketing mix memengaruhi secara langsung akan perspektif konsumen dalam media online. 
Tabel 4 Hasil uji model PLS

Sumber: Smart PLS 3.0

\begin{tabular}{lccc}
\hline \multicolumn{1}{c}{ Hipotesis } & Path Coef. & t-value & Hasil \\
\hline $\begin{array}{l}\text { H1: Price => Customer } \\
\text { Loyalty }\end{array}$ & 0.164 & 1.222 & Ditolak \\
\hline $\begin{array}{l}\text { H2: Promotion => } \\
\text { Customer Loyalty }\end{array}$ & 0.270 & $\mathbf{2 . 1 6 3}$ & Diterima \\
\hline $\begin{array}{l}\text { H3: Product => Customer } \\
\text { Loyalty }\end{array}$ & 0.079 & 0.785 & Ditolak \\
\hline $\begin{array}{l}\text { H4: Place => Customer } \\
\text { Loyalty }\end{array}$ & 0.254 & 1.652 & Ditolak \\
\hline $\begin{array}{l}\text { H5: Word Of Mouth }=> \\
\text { Customer Loyalty }\end{array}$ & 0.225 & $\mathbf{2 . 0 8 3}$ & Diterima \\
\hline $\begin{array}{l}\text { H6: Marketing Mix }=> \\
\text { Word Of Mouth }\end{array}$ & $\mathrm{R}$ & $\Delta \mathbf{R}^{\mathbf{2}}$ & \\
\hline
\end{tabular}

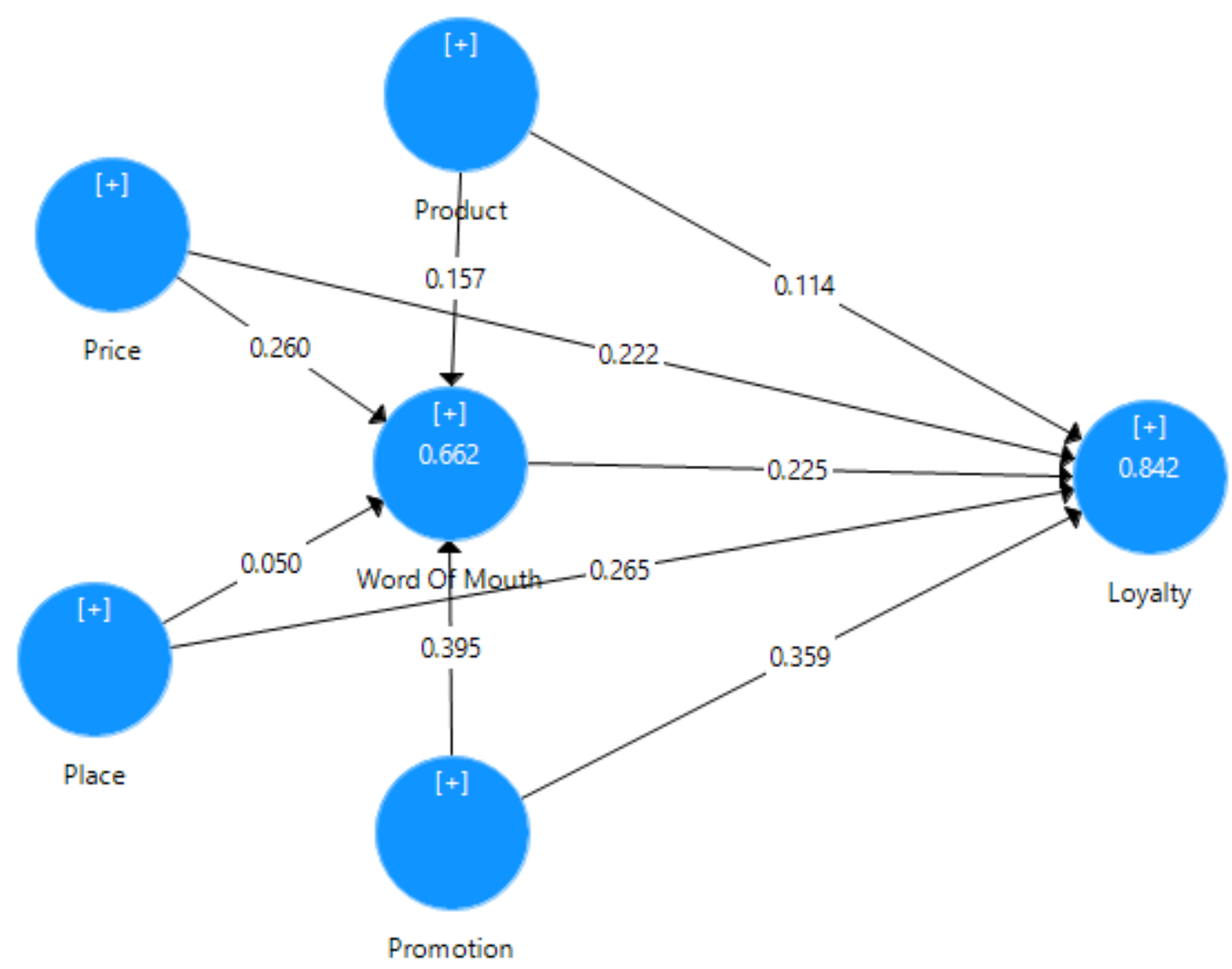

Gambar 1. Model PLS

Sumber : Smart PLS 3.0 


\section{KESIMPULAN DAN SARAN}

Penelitian ini bertujuan untuk menjawab gap penelitian dalam markering mix dengan digital marketing dimana model 4P yaitu Price, Promotion, Product, dan Place menjadi faktor yang menjelaskan word of mouth dan faktor terhadap loyalitas pelanggan. Penelitian ini memperoleh kesimpulan sebagai berikut; Pertama, peran marketing mix masih mampu sebagai salah satu pilihan strategi pemasaran merupakan hal yang dapat menjadi daya saing bagi perusahaan retail seperti Onitzua. Sebagai new entrants dalam sportswear dan casual aparrel merk ini mampu bertahan dengan pesaing yaitu raksasa retail seperti Nike dan Adidas. Dengan bermodalkan promosi yang memperkenalkan diri sebagai aparel berkualitas asal Jepang, Onitsuka dapat bersaing dengan pemain - pemain lama. Di sisi lain penelitian ini memiliki hasil yang berbeda dengan Setiawan (2019) yang juga meneliti peran marketing mix dalam retail terhadap loyalitas konsumen. Dalam penelitiannya ditemukan harga, produk, dan lokasi berperan penting terhadap loyalitas pelanggan. Demikian juga penelitian dari Othman et al. (2019) yang menjelaskan pengaruh marketing mix terhadap loyalitas pelanggan yang menemukan 7Ps sebagai faktor yang sangat berpengaruh dalam industri jasa. Perbedaan hasil ini yang menjadi kebaruan dalam mengelola strategi pemasaran. Berbeda dengan penelitian sebelumnya yang fokus pada service marketing mix 7Ps, penelitian ini menggunakan 4P sebagai strategi utama dalam product marketing. Dengan demikian penggunaan promosi melalui media sosial sebagai salah satu daya saing dapat menjadi pilihan strategi bagi perusahaan baru yang ingin masuk ke dalam industri pakaian dan sepatu di Indonesia. Namun harus dipastikan bahwa produk memiliki nilai unik yang dapat dijadikan daya saing yang unggul agar dapat bisa bertahan seperti yang dilakukan oleh Onitsuka yang mempromosikan nilai kualitas Jepang sebagai salah satu daya saing.

Temuan lain yang diperoleh dari hasil penelitian ini adalah marketing mix 4P yang dapat menjelaskan word of mouth. Hal ini sejalan dengan pendapat dari Saikh et al. (2018) yang mengatakan bahwa peranan promosi, produk, lokasi, dan harga menjadi faktor - faktor yang membentuk persepsi sebuah entitas perusahaan melalui word of mouth. Hasil penelitian ini menemukan bahwa loyalitas dihasilkan oleh word of mouth yang baik antar pelanggan dan lingkungan. Sebagai pemain baru informasi yang beredar di masyarakat sangat dipengaruhi oleh kualitas produk, lokasi strategis, promosi yang baik, dan harga yang kompetitif. Strategi marketing mix berpengaruh terhadap word of mouth yang ada di masyarakat sehingga dapat menciptakan loyalitas pelanggan. Dengan demikian dapat disimpulkan peran word of mouth dinilai penting dalam peningkatan loyalitas pelanggan dalam era kompetisi digital.

Pada penelitian selanjutnya dapat menambahkan faktor lain yang dapat memengaruhi perilaku atau strategi marketing dari perusahaan new entrants. Dengan perkembangan teknologi yang begitu cepat pesaing tidak hanya timbul dari pemain lama melainkan dari pemain kecil dan menengah yang mencoba mengambil pangsa pasar perusahaan baru. Hal ini menarik untuk diteliti lebih lanjut guna menghasilkan strategi marketing ditengah disrupsi kompetisi digital.

\section{REFERENSI}

Ahmad, S., Zulkarnain, N. N. ., \& Khairushalimi, F. (2016). Assessing the validity and reliability of a measurement model in Structural Equation Modeling (SEM). Journal of Advances in Mathematics and Computer Science, 1-8. Retrieved from http://www.journaljamcs.com/index.php/JAMCS/article/view/23445

Anderson, J., \& Gerbing, D. (1991). Predicting the performance of measures in a confirmatory factor analysis with a pretest assessment of their substantive validities. Journal of Applied Psychology, 76(5), 732. Retrieved from https://psycnet.apa.org/record/1992-03961-001

Ang, C., \& Rusli, H. (2018). The Impact of Marketing Mix 4Ps and Consumer Behavior toward 
Purchase Decision of Adidas Products. IBuss Management, 6(2). Retrieved from http://publication.petra.ac.id/index.php/ibm/article/view/7594

Damar, M. (2017). Spring of Life. Pt Eastspring Investments, 1(September), 1-6.

Dost, F., Phieler, U., Haenlein, M., \& Libai, B. (2019). Seeding as Part of the Marketing Mix: Word-of-Mouth Program Interactions for Fast-Moving Consumer Goods. Journal of Marketing, 83(2), 62-81. https://doi.org/10.1177/0022242918817000

Etikan, I., Abubakar Musa, S., \& Sunusi Alkassim, R. (2016). Comparison of Convenience Sampling and Purposive Sampling. American Journal of Theoretical and Applied Statistics, 5(1), 1-4. https://doi.org/10.11648/j.ajtas.20160501.11

Hair, J. F., Risher, J. J., Sarstedt, M., \& Ringle, C. M. (2019). When to use and how to report the results of PLS-SEM. European Business Review, 31(1), 2-24. https://doi.org/10.1108/EBR-11-2018-0203

Harsono, R. (2016). The Impact of Marketing Mix (4p's) on Customer Loyalty Towards Toyota Avanza. IBuss Management, 4(1). Retrieved from http://publication.petra.ac.id/index.php/ibm/article/view/5329

Indonesia Sportswear Industry | GBG. (2017). Retrieved March 30, 2020, from Global Business Guide Indonesia website: http://www.gbgindonesia.com/en/manufacturing/article/2017/indonesia_s_sportswear_indu stry_strong_growth_from_exports_and_domestic_sales_11710.php

LaPointe, P. (2011). The rock in the pond: how online buzz and offline WOM can make a strong message even more powerful. Journal of Advertising Research, 51(3), 456-457. Retrieved from http://www.journalofadvertisingresearch.com/content/jadvertres/51/3/456.fulltext.pdf

Lee, L. W. Y., Tang, Y., Yip, L. S. C., \& Sharma, P. (2018). Managing customer relationships in the emerging markets - guanxi as a driver of Chinese customer loyalty. Journal of Business Research, 86, 356-365. https://doi.org/10.1016/j.jbusres.2017.07.017

Maulani, T. S. (2017). The effectiveness of promotional mix toward image of the thematic day in bandung. International Journal of Business, Economics and Law, 12(2), 26-34. Retrieved from https://www.ijbel.com/wp-content/uploads/2017/05/BUS-20.pdf

Mulyana, A., \& Management, S. P. (2018). Determinants of Customer Satisfaction And it's Implication on Customer Loyalty of Budget Hotel in DKI Jakarta. International Review of Management and Marketing, 8(6), 1. Retrieved from http://search.proquest.com/openview/c7a1aa7937bebc40eccc721cf67d95a9/1?pqorigsite $=$ gscholar\&cbl $=816339$

Othman, B., Harun, A., Rashid, W. N., Nazeer, S., Kassim, A., \& Kadhim, K. (2019). The influences of service marketing mix on customer loyalty towards Umrah travel agents. Management Science Letters, 9(6), 865-876. https://doi.org/10.5267/j.msl.2019.3.002

Saleem, M. A., Yaseen, A., \& Wasaya, A. (2018). Drivers of customer loyalty and word of mouth intentions: moderating role of interactional justice. Journal of Hospitality Marketing and Management, 27(8), 877-904. https://doi.org/10.1080/19368623.2018.1469447

Sari, O. H. (2017). Influence Of Marketing Mix And Customer Relationship Management On Customer Loyalty In Pt. Abc In Jakarta. Jurnal Manajemen Bisnis Dan Kewirausahaan, 1(2). https://doi.org/10.24912/JMBK.V1I2.4793

Setiawan, Y. (2019). Analysis Retail Marketing Mix and Customer Loyalty. International Journal Management Science and Business, 1(1). Retrieved from http://ejournal.upi.edu/index.php/msb/article/view/17364

Shaikh, A. A., Karjaluoto, H., \& Häkkinen, J. (2018). Understanding moderating effects in increasing share-of-wallet and word-of-mouth: A case study of Lidl grocery retailer. Journal of Retailing and Consumer Services, 44, 45-53. 
https://doi.org/10.1016/j.jretconser.2018.05.009

Sriram, K., Phouzder, K., Mathew, A., \& Hungund, S. (2019). Does e-marketing mix influence brand loyalty and popularity of e-commerce websites? ABAC Journal, 39(2).

Sudari, S., Tarofder, A., Khatibi, A., \& Tham, J. (2019). Measuring the critical effect of marketing mix on customer loyalty through customer satisfaction in food and beverage products. Management Science Letters, 9(9), 1385-1396.

Warrington, T. (2002). The Secrets of Word-of-Mouth Marketing: How to Trigger Exponential Sales through Runaway Word of Mouth. Journal of Consumer Marketing, 19(4), 364-366. https://doi.org/10.1108/jcm.2002.19.4.364.4

Wu, Y. L., \& Li, E. Y. (2018). Marketing mix, customer value, and customer loyalty in social commerce: A stimulus-organism-response perspective. Internet Research, 28(1), 74-104. https://doi.org/10.1108/IntR-08-2016-0250 